\title{
The Study of Disagreement Strategies to Suggestions Used by Iranian Male and Female learners
}

\author{
Samira Salehipour Bavarsad ${ }^{1 *}$, Abbass Eslami-Rasekh², Shahla Simin ${ }^{1}$ \\ ${ }^{1}$ English Department, Najafabad Branch, Islamic Azad University, Najafabad, Iran \\ ${ }^{2}$ Faculty of Foreign Languages, English Department, University of Isfahan \\ *E-mail address: Samira.salehipour@gmail.com
}

\begin{abstract}
This study seeks to investigate the ways in which the speech act of disagreement is expressed by young male and female Persian speakers. To collect the data 100 participants (50 males, 50 females,) were selected randomly from among undergraduate and graduate students of University of Isfahan and Islamic Azad University (Najafabad branch). The focus of this study was on the role that gender and power might play in the employment of strategies to mitigate the threat of disagreement. Students were asked to complete a discourse completion test (DCT) designed by the researcher. They were supposed to read nine suggestions situations, and react to them via making disagreements. Respondents were expected to disagree with three interlocutors with higher status, three peers and three with lower status. In order to analyze the utterances of disagreement, Muntigl and Turnbull's taxonomy (1998) was employed. The results revealed that although both males and females were concerned about the power status of interlocutors and try to apply the appropriate strategies while expressing their disagreements, females were more cautious and used different strategies from those of males.
\end{abstract}

Keywords: Speech act of disagreement; suggestion; gender; power

\section{INTRODUCTION}

Clearly one of the goals of learning a foreign language is gaining the ability to communicate, to understand and be understood by native speakers of the language for which linguistic accuracy is not enough by itself. Therefore, the functions of speech have been the subjects of the study for not many years but for many researchers. These functions are employed as instruments to perform various actions such as expressing agreement and disagreement, refusing, making apology and requests, giving thanks, etc. (Yule, 1996); that some are considered face threatening by nature but polite strategies can be used to soften the treat to the face of interlocutors (Locher, 2004).

Due to misunderstanding among people from different cultures, people often fail to have successful communications. Although being polite is a universally acceptable concept, the meaning of politeness might vary across culture, gender, and power relations (Guodong \& Jing, 2005). For that reason, researchers need to investigate the denotation of politeness in different cultures and try to identify different patterns and discourse strategies. Kılıçkaya 
(2010) asserts that social, cultural, situational, and personal factors, which shape the eventual linguistic output of the L2 learners, complicate the situation for language learners in selecting and using certain kinds of speech acts.

Disagreement is the speech act which is considered as a face-threatening verbal behavior in which people can show their dissatisfaction or opposition; therefore, the application of politeness strategies is vital for maintaining face. It is evident that the degree of politeness is a variable under the effects of social factors including gender and power (Liu, 2004). Power as the major player in the process of selecting strategies has been defined in different ways; Brown and Levinson (1987) for example assert that "[p]ower is an asymmetrical social dimension of relative power"(p.77). But for Liu (2004) power means status in which professors, administrators, and students are on a hierarchy from powerful to powerless.

According to Liu (2004), disagreement is unavoidable in human interaction. It happens no matter how hard people try to avoid it; people face a very complicated condition when they try to avoid the unavoidable. There is always a contradiction between disagreement and face saving. When trying to soften their disagreement, people

need rhetorical strategies including both concepts of politeness and hierarchy. So the present study tries to answer following questions:

1. How do males and females perceive power and does this affect their disagreement strategies?

2. Does gender play a role in choosing the strategies for showing disagreement?

4. Do females use more polite strategies for showing disagreement?

\section{REVIEW OF RELATED LITERATURE}

As well as knowing the structure of a language, we have to know how to use it. According to Al-Tayib Umar (2006), acquisition of socio-cultural rules, which is widely known as pragmatic competence, is crucial to second language learners. Scollon and Scollon (1993) also assure that violation of pragmatic rules is bound to lead to communication breakdowns. Kasper (1999) states that, competences, whether linguistic or pragmatic, should be developed and learned systematically.

Politeness has become one of the most active areas of research in language use by increasing interest in Grice's (1975) Cooperative Principles (Chen, 2007). Acquisition and learning of politeness strategies is a part of learning L2 pragmatics, which has attracted a lot of attention in second and foreign language acquisition. In different cultures, politeness can be manifested and understood in different ways through both verbal and nonverbal behaviors. A large number of theoretical and empirical books and articles concerning politeness and/or the notion of face have been published in the last decades. In most of the studies, the politeness has been conceptualized especially as strategic conflict-avoidance or as strategic construction of cooperative social interaction (Watts 2003).

The face theory proposed by Brown and Levinson (1987) serves as the most influential theory on politeness. It plays an important role in the study of speech acts ( $\mathrm{Ji}, 2000$; Hobbs, 2003). Brown and Levinson's face theory contains three basic notions: face, face threatening acts (FTAs) and politeness strategies. Brown and Levinson (1987) argue that the concept of face is "the public self-image that every member wants to claim for himself" (p. 61). This public self-image comprises two desires. They argue that everyone in the society has two kinds of face wants. One is negative face: the basic claim to territories, personal preservers, 
rights to non-distraction, i.e. to freedom of action and freedom from imposition. The other is the positive face: the positive consistent self-image or 'personality' (crucially including the desire that this self-image be appreciated and approved of) claimed by interactants. Brown and Levinson built their theory of politeness on the assumption that many speech acts, for example requests, offers, disagreement and compliments, are intrinsically threatening to face. Speech acts are threatening in that they do not support the face wants of the speaker and those of the addressee inherently threaten either the hearer's or the speakers' face-wants and that politeness is involved in redressing those face threatening acts (FTA). On the basis of these assumptions, three main strategies for performing speech acts are distinguished: positive politeness, negative politeness and off-record politeness. Positive politeness aims at supporting or enhancing the addressee's positive face, whereas negative politeness aims at softening the encroachment on the addressee's freedom of action or freedom from imposition. The third strategy, off-record politeness, means flouting one of the Gricean (1975) maxims on the assumption that the addressee is able to infer the intended meaning.

Brown and Levinson (1987) defined face-threatening acts (FTAs) according to two basic parameters: "(1)Whose face is being threatened (the speaker's or the addressee's), and (2) Which type of face is being threatened (positive- or negative- face)" (p. 65). Acts that threaten an addressee's positive face include those acts in which a speaker demonstrates that he/she does not support the addressee's positive face or self image (e.g., complaints, criticisms, accusations, mention of taboo topics, interruptions). Acts that threaten an addressee's negative face include instances in which the addressee is pressured to accept or to reject a future act of the speaker (e.g., offers, promises), or when the addressee has reason to believe that his/her goods are being coveted by the speaker.

Examples of FTAs to the speaker's positive face include confessions, apologies, acceptance of a compliment, and self-humiliations. Some of the FTAs that are threatening to the speaker's negative face include expressing gratitude, accepting a thank-you, an apology or an offer, and making promises.

The kind and amount of politeness that the speaker applies to a certain speech act is determined by the weightiness of this speech act. Speakers calculate the weight of their speech acts from three social variables: the perceived social distance between the hearer and the speaker, the perceived power difference between them, and the cultural ranking of the speech act (Brown \& Levinson, 1987).

Although the studies on speech act of disagreement are less than other speech acts, being inherently a FTA, the speech act of disagreement has also aroused much attention in recent years (Rees-Miller, 2000; Muntigl \& Turnbull, 1998). Rees-Miller (2000), defines disagreement as: "A Speaker S disagrees when s/he considers untrue some Proposition P uttered or presumed to be espoused by an Addressee A and reacts with an utterance the propositional content or implicature of which is Not P" (1088).

The study by Parvaresh and Eslami (2009) designed to find the effects of solidarity and deference systems of politeness, proposed by Scollon and Scollon, on the use of strategy by women native speakers of Farsi while doing the speech act of disagreement. This study was an attempt to explore some of the differences that might appear between same-sex (femalefemale) and cross-sex conversations (male-female). Several expressions were used in order to disagree with what the other interlocutor had previously said. They ranged from highly impolite, rude responses to more polite one. The results indicated that in Iranian culture the addressee's gender highly affects the use of strategies while performing the speech act of disagreement even when there is a high amount of solidarity. It was found that women employ conflictives, which have the most impolite intention, mostly when and where the 
addressee is of the same sex. They argued that when men and women try to interact in crosssex conversations they do not play the same role in interaction, even when there is no element of flirting. The women used about three times fewer contradictory statements compared with the women in the woman-woman situation. For the women in the man-woman situation, the major pattern was a boast, but in the woman-woman situation the dominant pattern was the use of a curse. The number of complaints in man-woman situations was three times as much than the number of complaints in woman-woman situations. Again women in the womenwoman situation used more than twice as many contradictory statements as the women in the other situation did.

\section{METHODOLOGY}

\subsection{Introduction}

The present study is a part from a larger project, A Cross_Cultural and Inter_Cultural Study of Social Disagreement Strategies by Iranian EFL Learners and American, This study mainly aimed to investigate the roles of power and gender on the choice of appropriate strategies when employing the speech act of disagreement. To obtain the required data, a Discourse Completion Test (DCT) was distributed among 100 Iranian EFL graduate and undergraduate students. The DCT was designed by the researcher with the help of her professor.

\subsection{Participants}

The participants of this study consisted of 100 TEFL learners, including 50 males and 50 females, studying in Islamic Azad University, Najafabad branch, and also in University of Isfahan, Isfahan, Iran. The participants' age ranged from 19 to 36.

\subsection{Instruments}

To collect data for this study, a Discourse Completion Test (DCT) was designed and applied. The DCT is a form of questionnaire describing some natural situations to which the respondents are expected to react, making disagreement. In this case the (DCT) consists of nine scenarios, in which the subjects are expected to disagree with three higher statuses, three peers and three with a lower status and then, they will be asked to write their natural responses for each situation.

\subsection{Design}

This study adopted a survey design. In order to investigate the relationship between power and politeness in the realization of disagreements, the participants were given a DCT which consisted of nine scenarios. The questionnaire used here presented a brief description of certain situations, which specified the setting, the social distance between the interlocutors and their status relative to each other. When identifying the utterances of disagreement from the responses, the taxonomy of Muntigl and Turnbull (1998) was applied. 


\subsection{Procedure}

Prior to the actual data collection, the situations in the original studies were modified and adapted to suit the Iranian context. The modified form of the (DCT) was given to a professor for validation. His suggestions and observations were well taken into consideration in designing the final form of the (DCT). For further validation, the (DCT) was piloted on twenty subjects, similar to the main group, not included in the sample to see if the language was comprehensible for TEFL learners, and based on their responses a few changes were made.

The final DCT was administrated to participants. Selection of disagreement situations in DCT was based on social factor of relative power. The DCT consists of nine scenarios, in which the subjects were expected to disagree with three higher status, three with peers and three with a lower status. The questionnaire describes situations that Iranian participants may counter in everyday life and seeks to elicit responses to such situations and all of these situations were grouped according to power and distance among interlocutors. The scenarios covered a variety of topics and types of situations to avoid intervening effects of topic selection. The participants were asked to produce appropriate disagreement utterances for a given context of situation in DCT.

\section{RESULTS AND DISCUSSION}

This study adopted a survey design. Data required for the study were analyzed in three steps. First, invalid responses were discarded and the total number of valid responses was determined. In the second step, for identifying the utterances of disagreement from the responses, Muntigl and Turnbulls' (1998) taxonomy, which recognizes five types of disagreement, was used. Muntigl and Turnbull (1995, pp. 39-45) identify four types: Irrelevancy Claims (IC), Challenges (CH), Contradictions (CT) and Counterclaims (CC). In this taxonomy they rank the disagreement types from the most to the least face "aggravating". They define them as follows. Irrelevancy claim (IC) is the most face-threatening disagreement in which a speaker questions the relevancy of previous claim to the discussion at hand. The second disagreement type in this taxonomy is challenge $(\mathrm{CH})$ in which the speaker demands that addressee provide supporting evidence for his and her claim. Contradiction (C) is the next type of disagreement in which a speaker explicitly contradicts with the previous claim, but it is less face-threatening than IC and $\mathrm{CH}$ in that it does not decline the capability of other interlocutor. Another type of disagreement is counterclaim that is the least face-threatening act. In this case the speaker does not contradict directly. By bringing reason for disagreement and using positive markers, CC mitigates threat and damage to the others' positive face (Peter Muntigl 1995).

Beside these five types introduced by Muntigl and Turnbulls' taxonomy, the researcher could found four new patterns that were frequently used by Persian speakers which are closely related to the culture and power. These four patterns are introduced as Thanking (in which the disagreement to the situation starts with a thanking word), Mitigation of apology (in which the participants start their disagreement with a word af apology), Providing reason (in which the participant tends to give reason instead of showing direct disagreement), Mitigation of God willing (which is completely related to culture and religion). All these patterns are considered to mitigate threat and try to save the face of interlocutors as there is no direct contradiction. This analysis involved both qualitative and quantitative, independent 
examination of each response for the nine situations. Frequency of occurrence of these components learners is presented in two general tables.

\section{Situation 1}

You visit your doctor due to your continuous headaches. He believes that you must change your method of treatment but you are completely satisfied with this method and you disagree with the doctor.

You say: "

In this situation, inconsistency between the powers of interlocutors exists, since one speaker who is being disagreed with is of a higher power level due to his position. The data displayed a clear effect of the addressee's power on formulating the expression of disagreement.

\section{Situation 2}

You are driving on a highway that the police stops you and then fines you for not paying attention to the signs. He suggests you that it's better to participate in new classes of driving course which reeducates and reminds the signs. You feel no need to do this.

You say: " ..."

This situation seems to be exactly the same as previous one which shows disagreement with a male interlocutor in higher position and the same inconsistency exists between the powers of interlocutors.

\section{Situation 3}

You see your child's school principal. He tells you it's better to change your child's major because its future will not be so good. You think contrary to him and your child is successful in this field. Then you disagree with him.

You say:"

In this situation, the interlocutor who is disagreed with, is still a male in a higher position but in comparing with previous two situations the social power is considered to be less.

\section{Situation 4}

By coincidence, you see one of your old colleagues, Mr. Ahmadi, in the street and he tells you to change your hairstyle because it's not beautiful and you look older. Unlike him, you like this style a lot.

You say:"

In this situation, the interlocutors are status equal. Here, the major point which makes the difference is the gender of the speaker in scenarios.

\section{Situation 5}

You are speaking with a neighbor and she suggests changing the caretaker of the building because she isn't pleased with him, but you are completely satisfied with him and reject this suggestion. 
You say:" .."

Just like the forth situation within which gender was the determining factor, this situation and the sixth one seem to be similar, as here the interlocutors are status equal.

\section{Situation 6}

You buy a piece of clothes and come back home. When you put it on, your spouse says this color is not appropriate for you and it's better to change the color. You disagree.

You say:" ........................"

In this situation, the interlocutors are still equal but the close relationship between the spouses makes it different from the two previous situations.

\section{Situation 7}

Your babysitter offers you that one of your kids should be monitored by a psychiatrist. You think it's not necessary to do this and completely disagree with her.

You say:" ".

in this situation it is the speaker who possesses higher power status. So, the speaker finds himself completely free for choosing face threatening strategies ( irrelevance claims and challenges). In this situation gender also plays a significant role as women chose these face threatening strategies with the same gender.

\section{Situation 8}

You are sitting in a restaurant and ordering your favorite food. The waiter suggests not eating this food and trying the new one which is recently cooked in this restaurant. You disagree with his offer.

You say:"

Just like the previous situation, in this situation the person who is disagreed with is in lower status and the main focus is on the role of social distance in choosing an appropriate disagreement strategies.

\section{Situation 9}

You want to buy a house. The sweeper of that street tells you that there are a lot of problems in this quarter and it's better to buy a house two streets ahead. You have searched before and you are sure about your choice. You disagree with him.

You say:" ..."

In this last situation, again the power inconsistency is focused on as the interlocutor in this situation seems to have the least power status.Table 4.1 and figure 4.1 show and summarize the differences between males and females in applying an appropriate strategies to show disagreement according to the Muntigl and Turnbulls' taxonomy. 
Table 4.1. The differences between males and females in applying disagreement strategies.

\begin{tabular}{|c|c|c|c|c|c|}
\hline & \multirow{2}{*}{ Types of disagreement } & \multicolumn{2}{|c|}{ Male } & \multicolumn{2}{|c|}{ Female } \\
\hline & & $\mathrm{F}$ & $\mathrm{P}$ & $\mathrm{F}$ & $\mathrm{P}$ \\
\hline 1 & Irrelevancy claim & 34 & $7.55 \%$ & 11 & $2.44 \%$ \\
\hline 2 & Challenges & 22 & $4.88 \%$ & 34 & $7.55 \%$ \\
\hline 3 & Contradictions & 124 & $27.55 \%$ & 129 & $28.66 \%$ \\
\hline 4 & Counterclaims & 55 & $12.22 \%$ & 64 & $14.22 \%$ \\
\hline 5 & Contradictions followed by counterclaims & 20 & $4.44 \%$ & 21 & $4.66 \%$ \\
\hline
\end{tabular}

As Table 4.1 presents, men feel free to use face threatening strategies specially in applying IC (7.55\%) (e.g. You're not worth on money and fee!). Females tend to use $\mathrm{CH}$ strategy $(7.55 \%)$ which again is another face threatening strategy but it comes after IC which shows women are more cautious and use more polite strategies to show disagreement (e.g. Why doctor? It has worked well so far). According to the frequencies and percentages both males and females tend to use $\mathrm{C}$ strategy as it is more direct and shorter (e.g. No, this method is good). For women the least frequency goes to IC $(2.44 \%)$ and the most goes to C $(28.66 \%)$ while for men the least goes to CC (4.44) and the most goes to C $(27.55 \%)$. The CC strategy was used somehow equally by males and females (e.g. You can change the method of treatment but I do what I think is right for me).

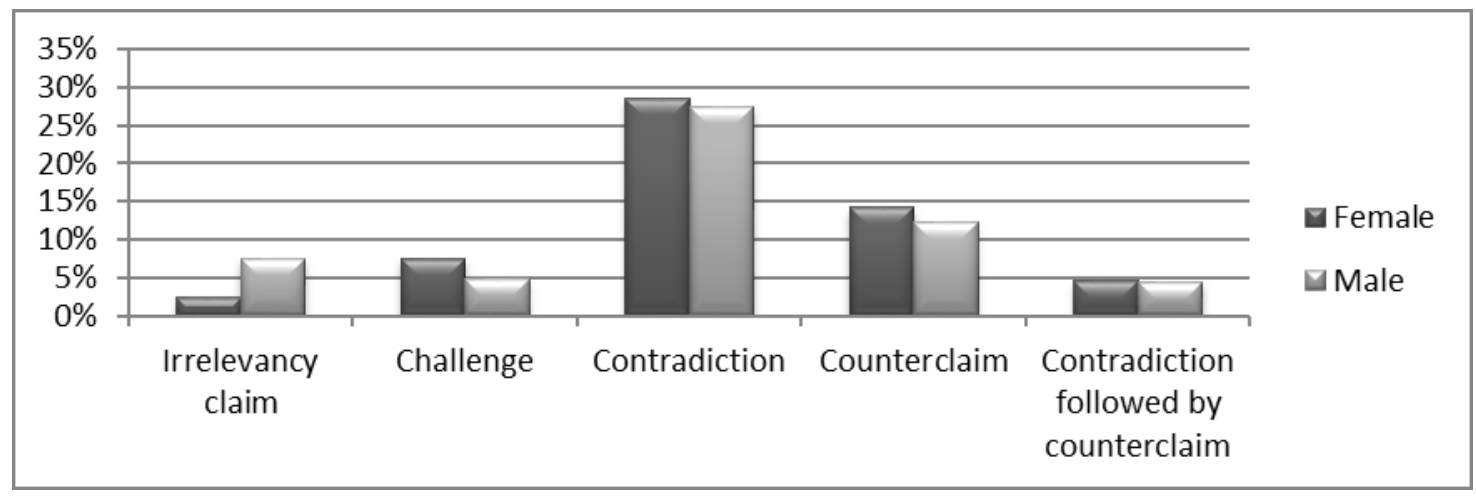

Figure 4.1. The differences between males and females in applying disagreement strategies.

As mentioned earlier, beside the strategies introduced by Muntigl and Turnbulls' taxonomy, the researcher found four other patterns that were used frequently by both males and females. Table 4.2 and figure 4.2 show and summarize the frequency and percentage of applying these patterns. 
Table 4.2. New patterns used by both males and females.

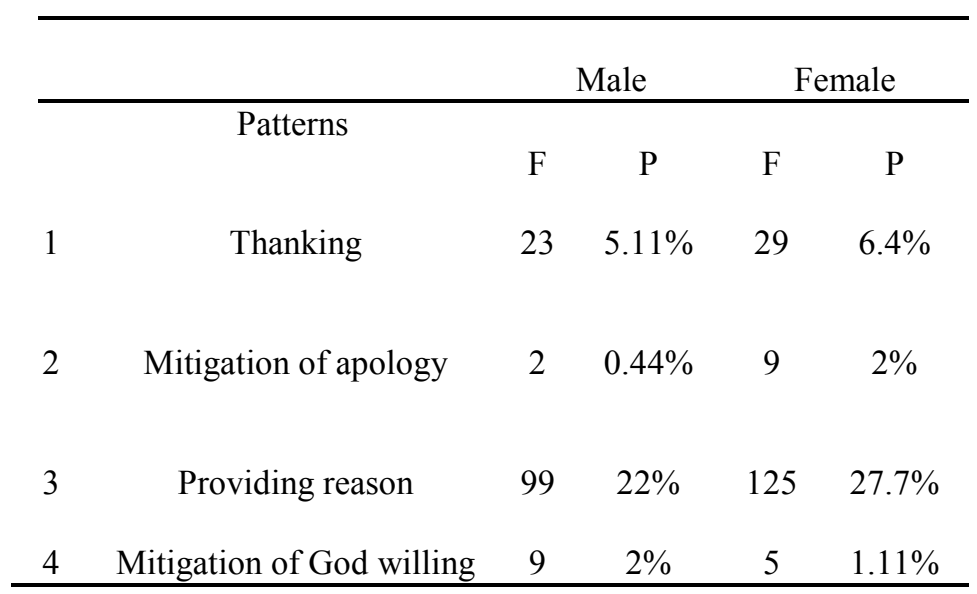

As the table shows, the high frequency of providing reason (male: $22 \%$, female: $27.7 \%$ ) proves that both males and females have a high tendency to keep the distance with the other interlocutor in conversations and try to keep the face of the addressee by not producing a direct contradiction (e.g. My spouse and I see his future rosy with this major). After 'providing reason', the highest frequency goes to 'thanking' (male:5.11, female: 6.4) (e.g. Thanks for your attention but my child's interest is more important than the future), Mitigation of God willing (male:2\%, female:1.11\%)(e.g. He tries and will be successful, God willing), and Mitigation of apology (male:0.44\%, female:2\%)( e.g. Sorry doctor but I don't like to change it) are the next used patterns in order.

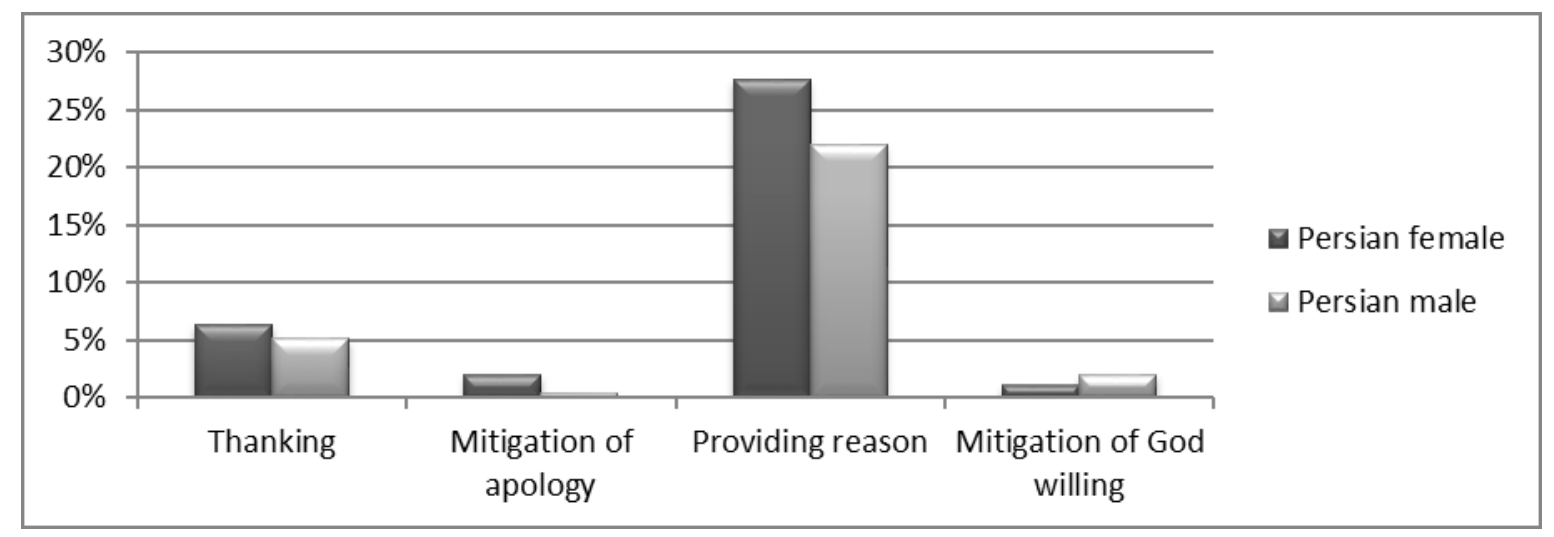

Figure 4.2. New patterns used by both males and females.

\section{CONCLUSION AND PEDAGOGICAL IMPLICATIONS}

The advanced and upper-intermediate Iranian EFL learners are capable of producing grammatically correct sentences but may still be incapable to produce language that is socially and culturally appropriate. So, there is a gap between the sentence and the context one should be aware of. The factors vary in choosing the correct strategy whether for agreement or disagreement. Most people in most circumstances experience a very complicated situation 
when they want to settle disagreements. The question of language and power is also a controversial issue in pragmatics, sociolinguistics, and sociology. Yet, it is among the least investigated areas in Persian language use, even in the field of general linguistics.

L2 learners may have access to the same range of speech acts and realizations as do native speakers, but they differ from native speakers in the strategies they choose. This may result from the lack of enough linguistic proficiency. In spite of the relatively long period of learning English and being highly proficient, Iranian EFL learners do not exhibit sufficient linguistic or socio-pragmatic skills that enable them to produce appropriate disagreement in English. This may be resulted from the inefficacy of the teaching methods and approaches adopted in Iran.

To help students realize maximum pragmatic success, teachers need to make their students fully aware of the specific speech act sets and the accompanying linguistic features to produce appropriate and acceptable complaint and other important speech acts (Tanck, 2002). The findings may provide information to people who are responsible for designing textbooks and classroom activities and materials for EFL learners. It is hoped that, the insights provided in this study will be helpful to the EFL teachers in understanding their students' language behavior and in revealing specific differences in the choice of certain politeness strategies that may need to raise learners' awareness of these differences.

\section{References}

[1] Al-Tayib Umar, A. M. (2006). The speech act of complaint as realized by advanced Sudanese learners of English. Umm Al-Qura University. Journal of Educational \& Social Sciences \& Humanities, 18(2), Jumada II 1427AH.

[2] Bargiela-Chiappini, F. (2003). Face and politeness: New (insights) for old (concepts). Journal of Pragmatics, 35, 1453-1469. http://dx.doi.org/10.1016/S0378-2166(02)00173X Brown, P., \& Levinson, S. (1987). Some universals in language usage. Cambridge: Cambridge University Press.

[3] Brown, P., \& Levinson, S. C. (1978). Universals in language usage: Politeness phenomena In EN Goody (Ed.), Questions and politeness: Strategies in social interaction, Cambridge (pp. 56-311). New York: Cambridge University Press.

[4] Fairclough, N. (1989). Language and Power. London: Longman.

[5] Gruber, H. (1998). Disagreeing sequential placement and internal structure of disagreements in conflict episodes. Text, 18, 467-503.

[6] Guodong, L., \& Jing, H. (2005). A contrastive study on disagreement strategies for politeness between American English \& Mandarin Chinese. Asian EFL Journal, 10(1).

[7] Hatch, E. (1992). Discourse and language education. Cambridge Language Teaching Library: Cambridge University press.

[8] Honda, A. (2002). Conflict management in Japanese public affairs talk shows. Journal of Pragmatics, 34, 573-608.

[9] Jalilifar, A. (2009). Request strategies: cross-sectional study of Iranian EFL learners and Australian native speakers. English Language Teaching Journal, 2(1), 790-803. 
[10]Ji, S. J. (2000). 'Face' and polite verbal behaviors in Chinese culture. Journal of Pragmatics, 32, 1059-1062.

[11]http://dx.doi.org/10.1016/S0378-2166(99)00068-5 Kakava, Ch. (2002). Opposition in modern Greek discourse: Cultural and Contextual constraints. Journal of Pragmatics, 34, 1537-1568.

[12]Kihekaya, F. (2010). The pragmatic knowledge of Turkish EFL students in using certain request strategies, 9(1), 185-201.

[13]Liu, S. (2004). Pragmatic strategies and power relations in disagreement: Chinese culture in higher education. New York: Universal Publishers.

[14]Locher, Miriam. )2004(. Power and politeness in action. Disagreements in oral communication. Berlin: Mouton de Gruyter.

[15]Moon, K. (2001). Speech act study: differences between native and nonnative speakers' complaint strategies. The American University. Retrieved from www.Science-directjournal.com

[16]Muntigl, P., \& Turnbull, W. (1998).Conversational structure and facework in arguing. Journal of Pragmatics, 29,225-256. http://dx.doi.org/10.1016/S0378-2166(97)00048-9 .

[17]Nelson, G., Al-Batal, M., \& El-Bakary, W. (2002). Directness vs. indirectness: Egyptian Arabic and US English communication style. International Journal of Intercultural Relations, 26, 39-57.

[18]Pearson, E. (1986). Agreement/disagreement: An example of results of discourse analysis applied to the oral English classroom. International Review of Applied Linguistics, 74(1), 47-61.

[19]Rees-Miller, J. (2000). Power, severity, and context in disagreement. Journal of Pragmatics,32(8), 1087-1111.

[20]Richard J. C., \& Schimidt R. (1985). Dictionary of language teaching \& applied linguistics. Longman: Pearson Education.

[21] Schmitt, N. (2002). An introduction to applied linguistics. New York: Oxford university press.

[22] Scott, S. (2002). Linguistic feature variations within disagreements: An empirical investigation. Text, 22(2), 301-328.

[23] Takano, S. (2005). Re-examining linguistic power: strategic uses of directives by professional Japanese women in positions of authority and leadership. Journal of Pragmatics, 37, 633-666. www.ccsenet.org/elt English Language Teaching Vol. 5, No. 10; 2012191

[24]Tannen, D., \& Kakava, Ch. (1992). Power and solidarity in modern Greek conversation: Disagreeing to disagree.Journal of Modern Greek Studies, 10, 11-34.

[25]Walko, Z. (2007). EFL research articles through the lens of pragmatic politeness. Retrieved from http://langped.elte.hu/Walko.pdf Watts, Richard J. (2003). Politeness. Cambridge: Cambridge University Press. 
[26]Yu, M. (2003). On universality of face: Evidence from Chinese compliment response behavior. Journal of Pragmatics, 35, 1679-1710. http://dx.doi.org/10.1016/S03782166(03)00074-2

[27]Yule, G.(1996). Pragmatics. Oxford: Oxford University Press.

\section{Appendix A}

\section{English Version of the Discourse Completion Test (DCT)}

Age: .......... Gender: ............... Degree:

Please read the following situations and answer. Researcher wants you to give appropriate answer in a completely normal manner. Thanks for your cooperation.

1.You visit your doctor due to your continuous headaches. $\mathrm{S} / \mathrm{H}$ e believes that you must change your method of treatment but you are completely satisfied with this method and you disagree with the doctor.

You say:

2.You're driving on a highway that the police stops you and then fines you for not paying attention to the signs. He suggests you that it's better to participate in new classes of driving course which reeducates and reminds the signs. You feel no need to do this.

You say:

3.You see your child's school principal. He tells you it's better to change your child's major because its future will not be so good. You think contrary to him and your child is successful in this field. Then you disagree with him.

You say:

4. By coincidence, you see one of your old colleagues, Mr. Ahmadi, in the street and he tells you to change your hairstyle because it's not beautiful and you look older. Unlike him, you like this style a lot.

You say:

5.You are speaking with a woman an neighborhood and she suggests changing the caretaker of the building because she isn't pleased with him, but you are completely satisfied with him and reject this suggestion.

You say:

6 . You buy a piece of clothes and come back home. When you put it on, your spouse says this color is not appropriate for you and it's better to change the color. You disagree.

You say:

7. Your babysitter offers you that one of your kids should be monitored by a psychiatrist. You think it's not necessary to do this and completely disagree with her.

You say: 
8. You are sitting in a restaurant and ordering your favorite food. The waiter suggests not eating this food and trying the new one which is recently cooked in this restaurant. You disagree with his offer.

You say:

9. You want to buy a house. The sweeper of that street tells you that there are a lot of problems in this quarter and it's better to buy a house two streets ahead. You have searched before and you are sure about your choice. You disagree with him.

You say: 